\title{
Micro failure analysis of adhesively bonded joints enhanced with natural cork particles: Impact of overlap length and particles volume fraction
}

\author{
Alireza Akhavan-Safar \\ Fatigue and Fracture Laboratory, School of Mechanical Engineering, Iran University of Science and Technology, 16846-13114, \\ Tehran, Iran. \\ Akhavan_Safar@iust.ac.ir \\ Ana Queirós Barbosa \\ INEGI, Rua Dr. Roberto Frias,400 4200-465, Porto, Portugal. \\ aqueiros@inegi.up.pt \\ Lucas Filipe Martins da Silva \\ Department of Mechanical Engineering, Faculty of Engineering, University of Porto, Rua Dr. Roberto Frias, 4200-465, Porto, \\ Portugal \\ Lucas@fe.up.pt
}

Majid Reza Ayatollahi

Fatigue and Fracture Laboratory, School of Mechanical Engineering, Iran University of Science and Technology, 16846-13114, Tehran, Iran.

m.ayat@iust.ac.ir

\begin{abstract}
In this work, the effects of natural particles on the micro failure mechanisms and static strength of an epoxy are studied using scanning electron microscope (SEM) technique. To this end, bulk specimens and adhesively bonded single lap joints (SLJs) containing different amount of micro cork particles were fabricated and tested. To investigate the toughening mechanisms, the fracture surfaces of the specimens were analyzed using SEM and a magnifying glass. It was shown that the deviation of the crack path and formation of micro-cracks generate multi fracture surfaces which is one of the main sources of energy absorption and resulted in higher fracture energy of the enhanced adhesives. Corks also acts as a crack stopper, stabilizes the crack propagation and prevents unstable crack growth. However, the micro analysis showed that higher contents of cork lead to agglomeration of the particles which acts as a source of stress concentration, with a higher possibility of delamination between the matrix and the micro corks. Accordingly, there is an optimum amount of cork where the best adhesive fracture toughness is reached. The results showed that the optimum value of micro particles depends on the loading conditions.
\end{abstract}

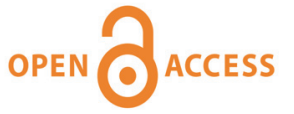

Citation: Akhavan-Safar, A., Ayatollahi, M.R., Queiros Barbosa, A., da Silva, L.F.M., Micro failure analysis of adhesively bonded joints enhanced with natural cork particles: Impact of overlap length and particles volume fraction, Frattura ed Integrità Strutturale, 46 (2018) 266-274.

Received: 20.05 .2018

Accepted: 15.08 .2018

Published: 01.10 .2018

Copyright: (C) 2018 This is an open access article under the terms of the CC-BY 4.0, which permits unrestricted use, distribution, and reproduction in any medium, provided the original author and source are credited. 
KEYwORDS. Epoxy; Micro cork particles; Micro Failure mechanisms; Fracture toughness; Volume fraction.

\title{
INTRODUCTION
}

\begin{abstract}
A pplications of adhesives and specially epoxy resins, as an alternative to traditional fasteners, have considerably increased in different industries [1,2]. Although epoxies show good mechanical properties, the structure of these thermoset polymers causes insufficient energy absorption with a low resistance to the propagation of cracks $[1,3$, 4]. For this reason, improving their toughness has been extensively studied in the last decades [5-7]. Adding cork particles to epoxies as a toughening method has been considered in some works $[8,9]$.

Cork is elastic and light and consists of different layers with honeycomb shape which make it interesting for engineering applications [10,11]. Cork's low thermal conductivity combined with a reasonable compressive strength makes it an excellent material for thermal insulation purposes and when compressive loads are present [10, 12]. Also, different researchers have considered the cork as a sound insulator [13]. However, some limited studies have investigated structural aspects of these natural particles. Barbosa et al. [8] studied the effect of size and volume fraction of cork particles on the impact toughness of adhesive bonding. In their analysis, the cork particles ranging from 38 to $250 \mu \mathrm{m}$ were considered. Also, the volume fraction of cork was changed from 1 to $5 \%$ by weight. According to their results, a small volume fraction of cork particles presents a better impact energy absorption than a large volume fraction of small particles. To investigate the effect of moisture on the degradation of an adhesive reinforced with micro cork particles, the same authors [9] studied the moisture effect on the adhesive enhanced with micro-cork particles. Their results showed that the cork particle does not have a great influence on the absorption/desorption of moisture. Barbosa et al. [14] also studied the effect of natural cork particles on the stress-strain behavior of an epoxy based adhesive. Their results showed that the cork particles cause higher ductility and improve the failure strain of the adhesive. In general, the cork particles have no direct influence on the curing process, although they slightly change the curing mechanism [15].

The current research deals with the assessment of the micro failure mechanisms of an epoxy enhanced with micro cork particles. The influence of the particle volume fraction on the strength of joints and bulk specimens was considered. To achieve this, single lap joints and dog-bone tensile specimens enhanced with various volume fractions of cork particles were manufactured and tested at room temperature. The fracture surfaces of the joints and bulk specimens were then analyzed using SEM technique and a magnifying glass.
\end{abstract}

\section{EXPERIMENTS}

\section{Materials and properties}

A raldite 2020, from Huntsman Advanced Materials (Pamplona, Spain) was used to bond the substrates. Tab. (1) gives the experimentally obtained mechanical properties of the tested epoxy. High strength steel was used as substrates to guarantee the elastic behavior of the adherends until joint failure. Cork particles of 125-250 $\mu \mathrm{m}$ size were also used to toughen the adhesive. It was shown in previous studies [8] that the mentioned size corresponds to the best mechanical properties of the composite resin/cork. The cork particles were supplied by Amorim Cork Composites (Mozelos, Portugal), without treatment. The particles used in the current paper are from a source similar to that of the previous study [16], and subsequently has the same size distribution shown in Fig. (1). Fig. (2) shows a typical structure of a micro cork particle.

\begin{tabular}{lc}
\hline Young's modulus $(\mathrm{E})$ & $2.7 \mathrm{GPa}$ \\
Poisson's ratio $(v)$ & 0.37 \\
Maximum tensile strength $\left(\sigma_{\max }\right)$ & $55 \mathrm{MPa}$ \\
Maximum tensile strain $\left(\varepsilon_{\max }\right)$ & $3.5 \%$ \\
\hline
\end{tabular}

Table 1: Mechanical properties of the adhesive. 


\section{SLJs and bulks manufacture}

The cork particles were mixed into the resin by SpeedMixer DAC 150TM using a centrifugal technique, to decrease the introduction of air bubbles and produce a uniform distribution of particles. The speed and mixing time were set to 1500 $\mathrm{rpm}$ and 90 seconds respectively. Initially, cork was mixed with the resin and the hardener was added later to the mixture. This procedure was the same for the different cork volume fractions. To manufacture the bulk specimens the mixture was cast in a mold. The tensile specimens were then machined into their final shapes. A typical bulk specimen is shown in Fig. (3).

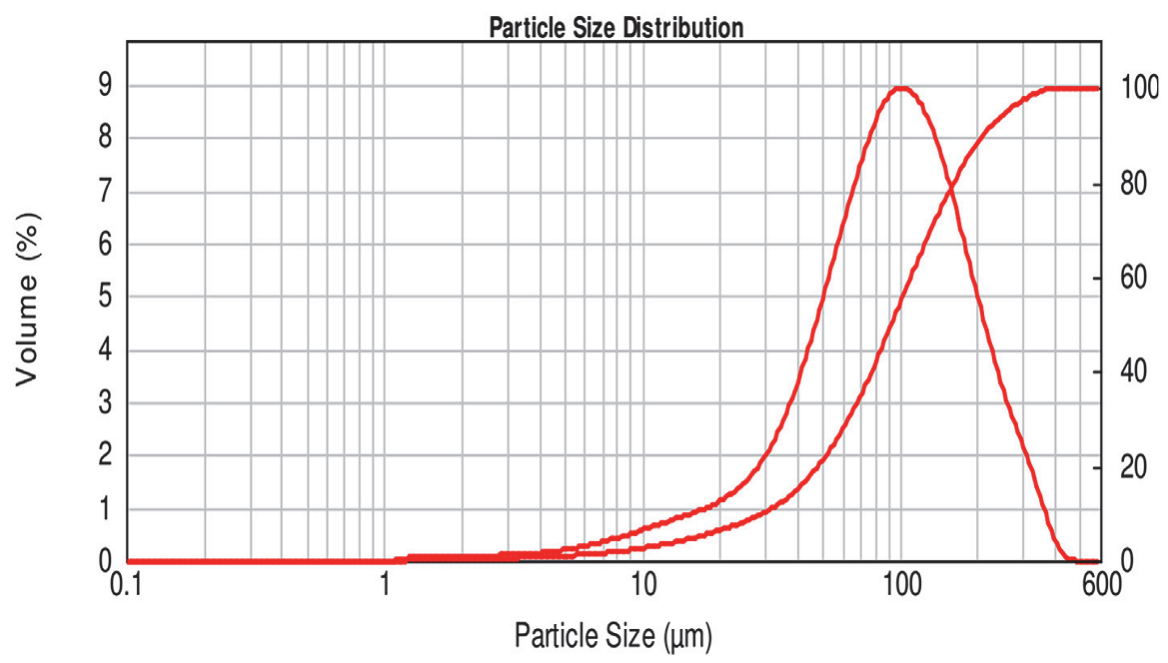

Figure 1: Particle size distribution of cork particles with 125-250 $\mu \mathrm{m}$ size [16].

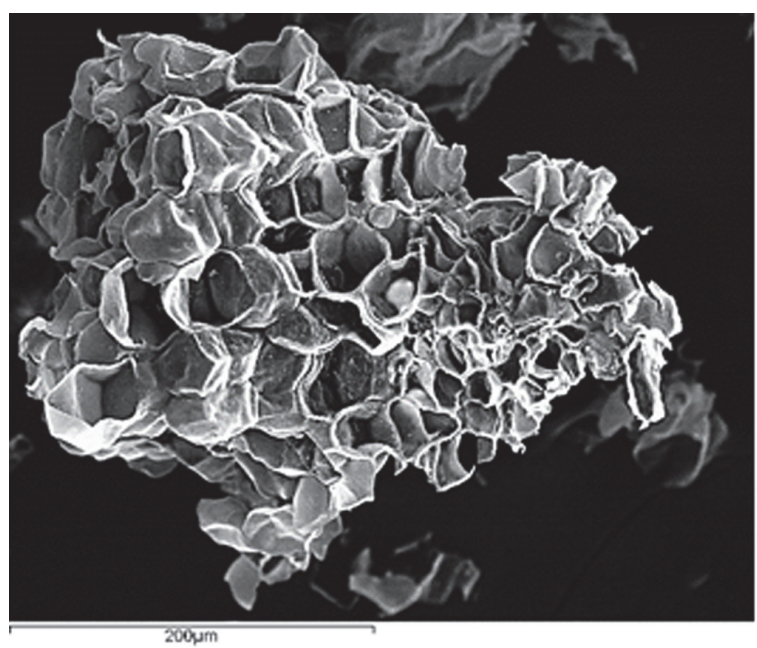

Figure 2: Microstructure of a micro cork particle with $125-250 \mu \mathrm{m}$.

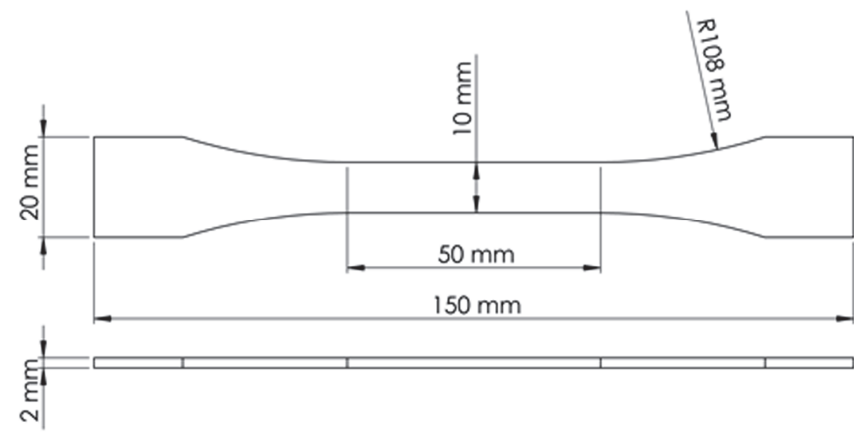

Figure 3: Dimensions of the bulk specimens. 
Before manufacturing the joints, the substrate surfaces were firstly pre-treated using sand blast technique. To do this a brown fused alumina with average dimension of $710 \mu \mathrm{m}$ at pressure of 6.5 bar was used to clean the substrate surfaces. After sand blasting, the surfaces were cleaned with acetone. Fig. (4) shows the dimensions of the manufactured SLJs. To cure the adhesive, the SLJs and the bulk plates were hot pressed at 14 bar for 15 minutes at $100^{\circ} \mathrm{C}$. To investigate the effect of cork density on mechanical properties of the adhesive and on the strength of SLJs, adhesive joint samples containing different volume fractions of cork particles (including 1\%,2\% and $5 \mathrm{vol} \%$ ) were considered.

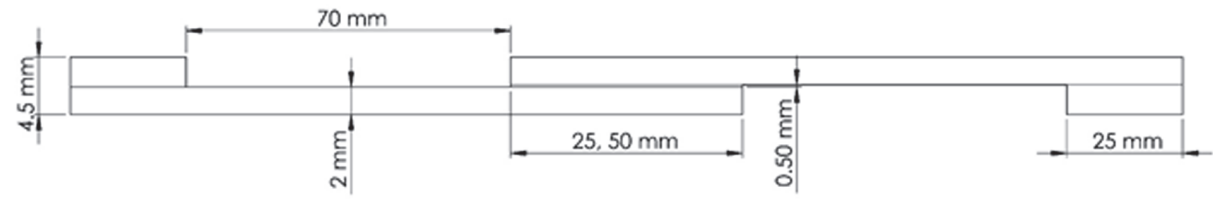

Figure 4: Dimensions of the tested joints.

SLJ and bulk tests

Tab. (2) gives the configurations of the joints tested. The tests were carried out under displacement control condition at 1 $\mathrm{mm} / \mathrm{min}$. End-tabs were fixed at the end of all the joints as shown in Fig. (4), to reduce the bending effect. At least three specimens for each configuration were manufactured and tested.

\begin{tabular}{lc}
\hline \multicolumn{2}{c}{ Test parameters } \\
Cork volume fraction $(\%)$ & $0,1,2$ and 5 \\
SLJ overlap length (mm) & 25 and 50 \\
\hline
\end{tabular}

Table 2: Configurations of the tested joints.

\section{Fracture surface analysis}

A magnifying glass and SEM were used to perform a careful analysis of the fracture mechanisms and toughening phenomena. For this purpose, a magnifying glass (Zeiss/Germany) was used in conjunction with an image capture software, Leica LAS 4.3 (Leica Microsystems/Germany). SEM analyses were also performed to investigate the distribution of the cork particles and to analyze the fracture surface of the joints specimens. To achieve this, a JEOL JSM 6301F/Oxford INCA Energy 350/Gatan Alto 2500 microscope (Tokyo, Japan) were used, at CEMUP (University of Porto, Portugal). Samples were coated with an $\mathrm{Au} / \mathrm{Pd}$ thin film, by sputtering, using the SPI Module Sputter Coater equipment, for $120 \mathrm{~s}$ and with a $15 \mathrm{~mA}$ current.

\section{RESULTS AND DISCUSSIONS}

he volume fraction of particles dispersed in a structural adhesive matrix is usually a significant parameter in controlling the resulting properties of the toughening adhesive. Authors showed that toughness increases with an increasing volume of particles and eventually reaches a maximum value [4]. Fig. (5) shows typical loaddisplacement curves of bulk specimens with different amounts of corks. As shown in Fig. (5), bulks with 1 vol\% micro particles give higher elongation at break.

Fig. (6) shows the fracture surface of the tested bulk specimens for different cork volume fractions. Fig. (6) shows that the micro cork particles cause several cleavage failures, which result in a higher energy absorption and consequently higher toughness of the adhesive. According to Fig. (6), cleavage in the fracture surface of the bulk specimens with 1 vol\% cork is higher than the adhesive with no-cork or $5 \mathrm{vol} \%$ micro particles. Using a higher fraction of cork particles cause formation of more voids and more air entrapment. Since the tensile strength of the bulk specimens is highly sensitive to the presence of voids, higher density of bubbles considerably decreases the static strength of the specimens. Formation of micro cracks around the voids and subsequently the void coalescence are the main reasons of the lower static strength of bulks with 5 vol $\%$ cork particles. These results are in agreement with the previously published data. In previous studies, 
Barbosa et al. [14] established that the mechanical properties of the adhesive change with the presence of cork. For tensile tests, the volume fraction having the highest strength is 1\%, showing an increase relative to the neat resin (see Fig. (7)).

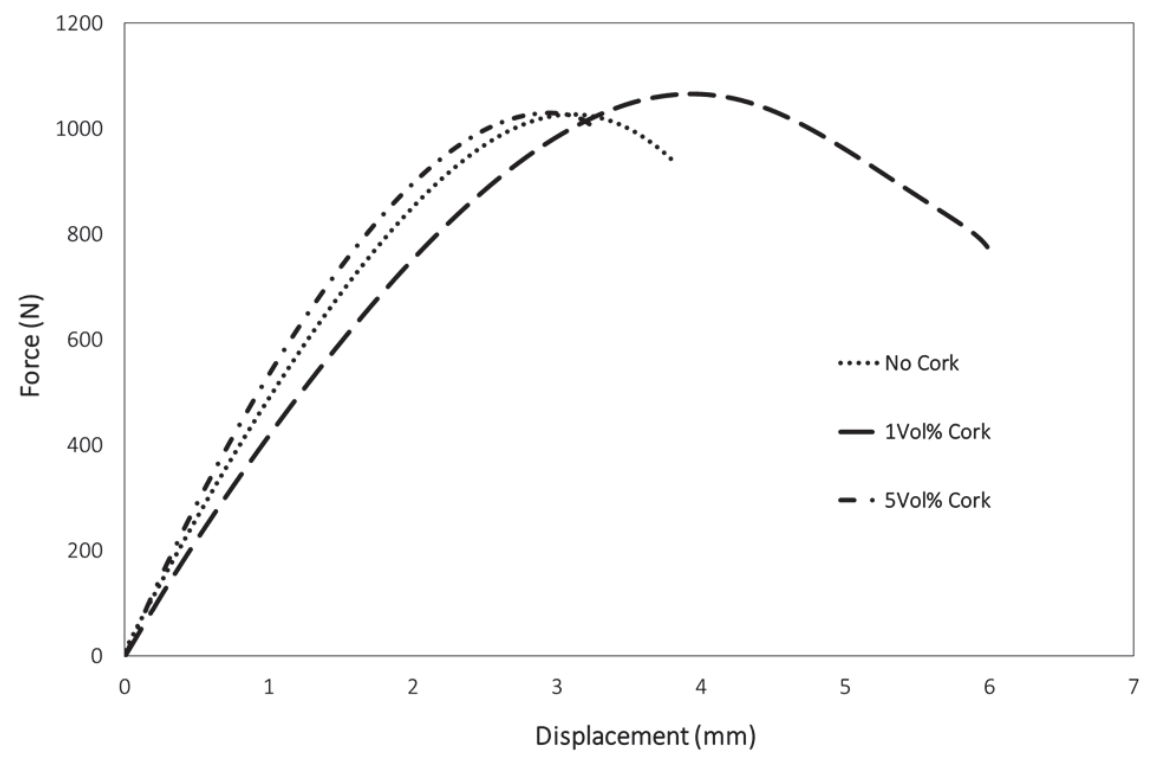

Figure 5: Typical load-displacement curves of bulks with different amounts of corks.
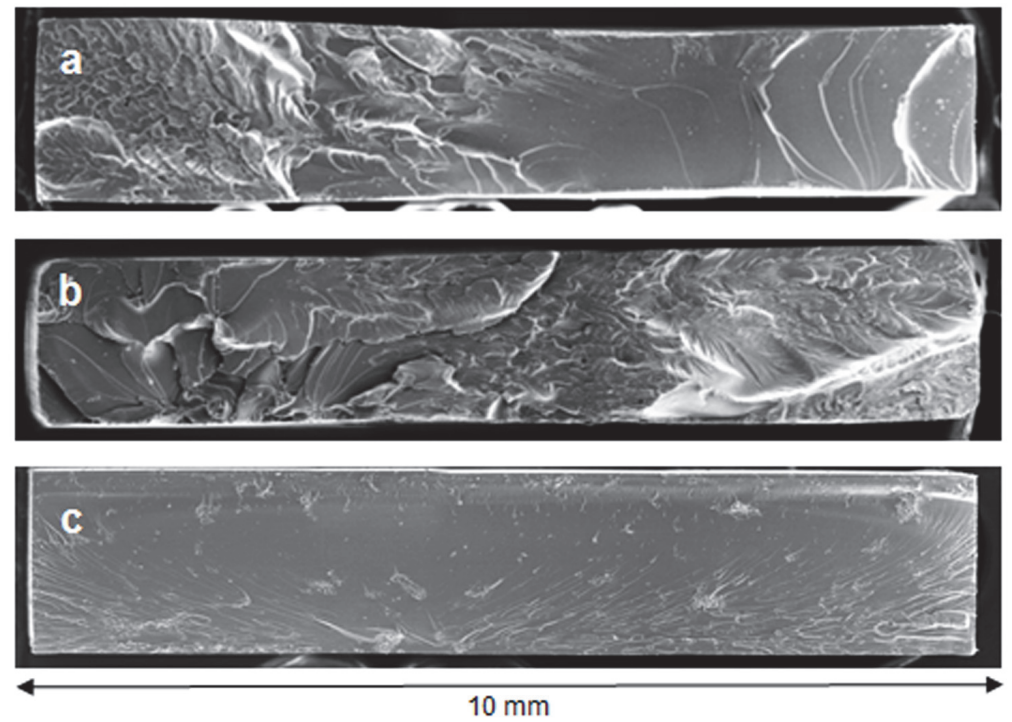

Figure 6: Fracture surface of bulk tensile specimens at room temperature with (a) no-cork, (b) 1 vol $\%$ cork and (c) 5 vol $\%$ cork.

SLJs were tested varying the overlap length and the cork volume fraction. Micrographs of fracture surfaces of the SLJs with neat adhesive and with 1 vol\% of cork are shown in Fig. (8). Fig. (9) shows the average shear stresses of SLJs with different overlap lengths and as a function of cork volume fraction. As shown in Fig. (9), the strength of the SLJs increase with cork volume fraction. A possible reason for the higher energy absorption of the cork modified adhesive is the deviation of crack path due to the presence of cork particles. The deviation of the crack path during the failure process cause an increase of the crack surface area. This phenomenon is one of the main sources of energy absorption which resulted in higher fracture energy of the modified adhesive joints. Acting as a crack stopper and consequently stabilizing the crack propagation prevents developing large and unstable cracks which is another source of energy consumption which increases the fracture energy of the tested material. However, it should be noted that further increase of the volume fraction of the micro cork particles leads to lower static strength of the joints and bulk specimens. The failure analysis showed that higher volume fractions of cork increases the presence of voids and raise the possibility of weak adhesion 
between the particles and the matrix. In addition, it should be noted that by increasing the density of particles, the possibility of agglomeration of the particles increase as well.

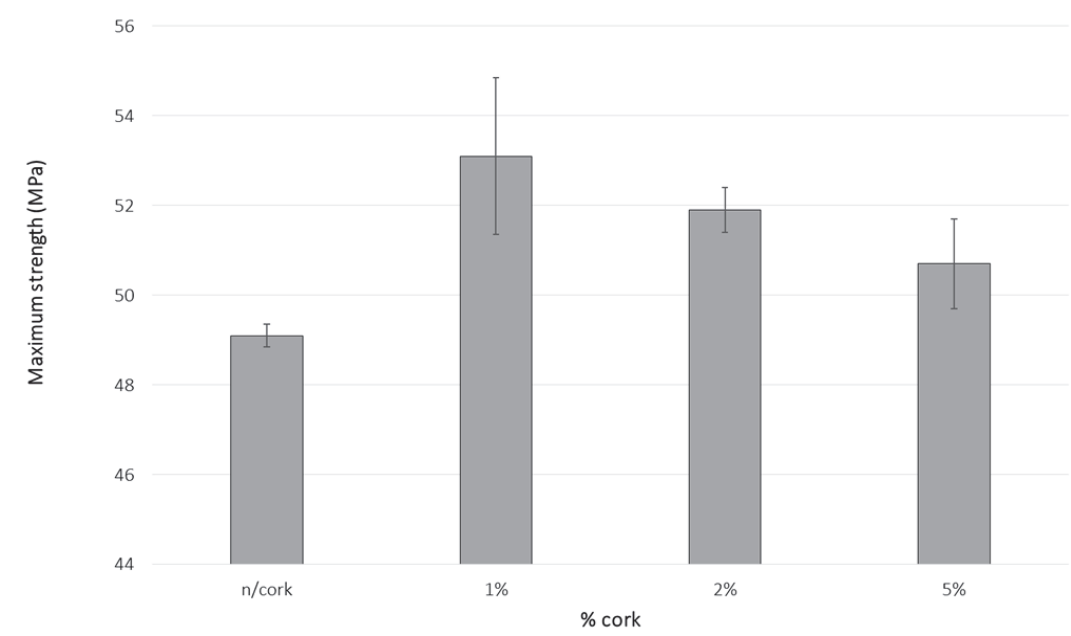

Figure 7: Maximum strength of bulk specimens with different cork volume fraction [14].

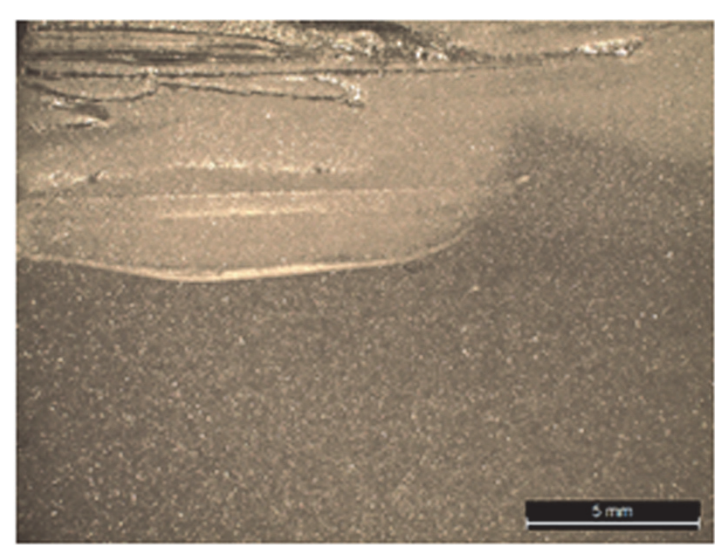

$1 /$ cork

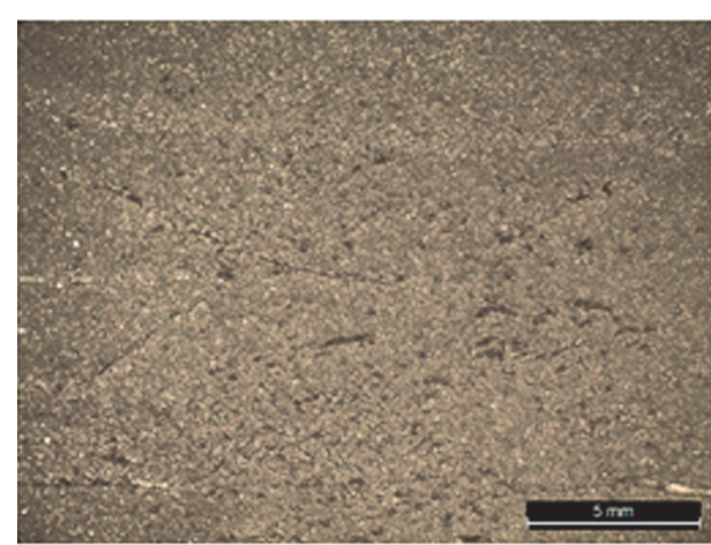

$1 \%$ cork

Figure 8: Micrographs of fracture surfaces of the SLJs with neat adhesive and with 1\% cork.

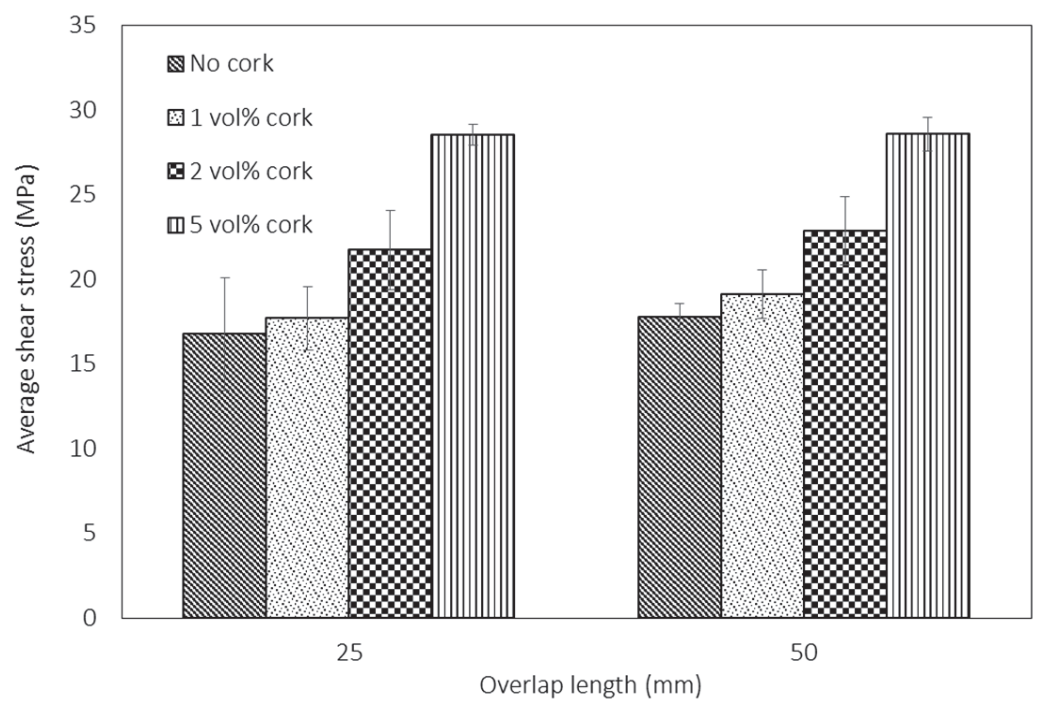

Figure 9: Average shear stresses of SLJs with different overlap lengths and various volume fractions of cork particles. 


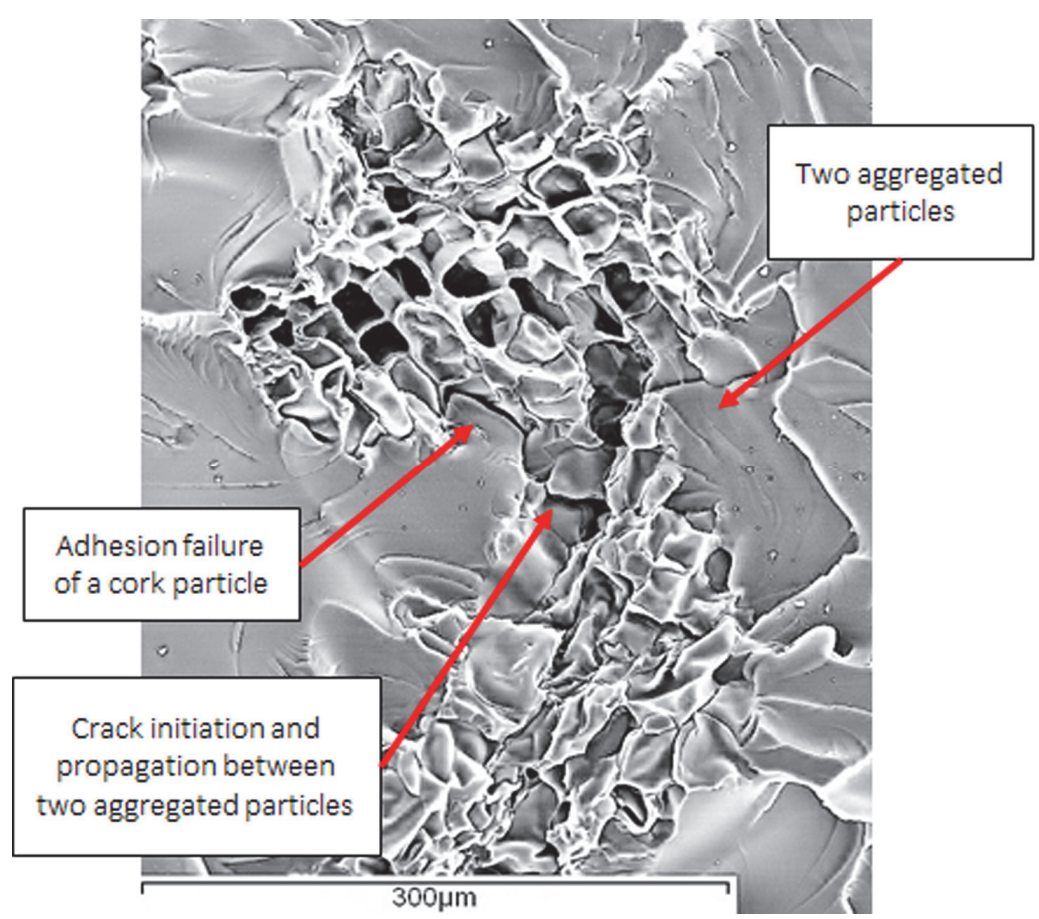

Figure 10: Different failure phenomena caused by cork particles.

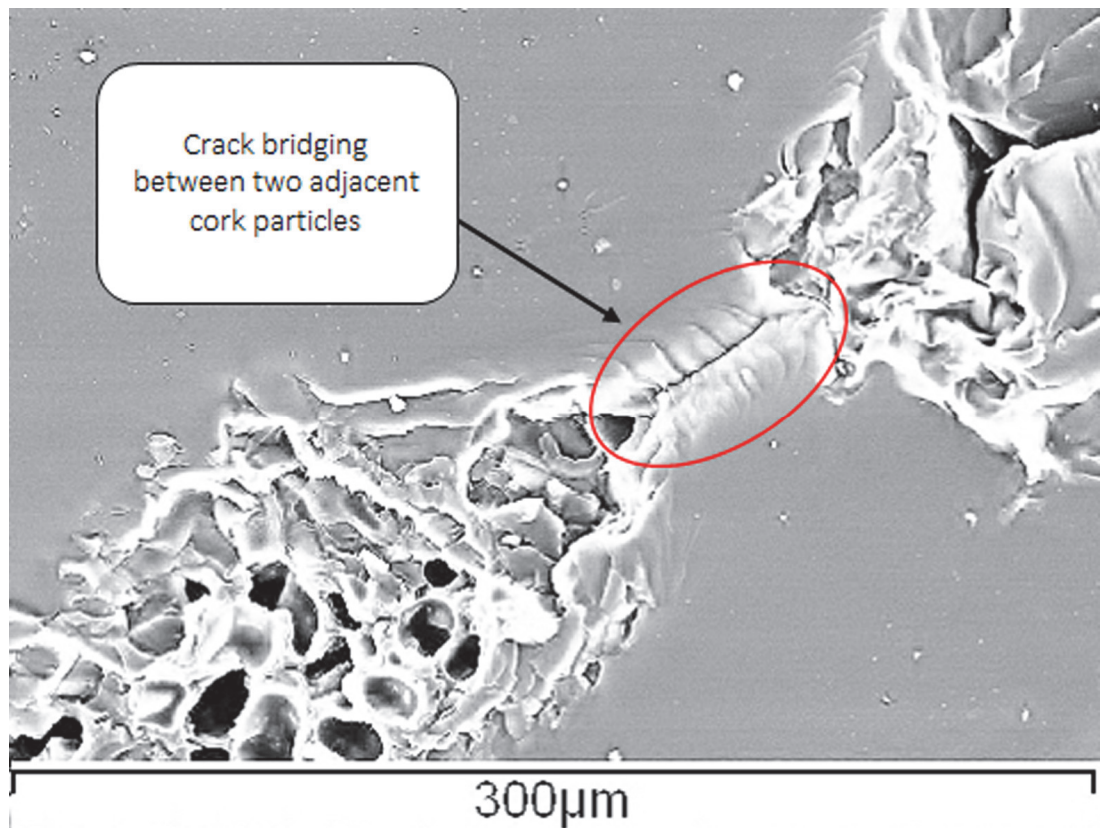

Figure 11: Crack initiation and propagation between two adjacent cork particles.

Fig. (10) shows two aggregated particles. Cork agglomeration increases the stress concentration areas and subsequently decreases the joint strength. Higher cork density also causes a decrease of the adhesive thickness between two adjacent particles, which results in the weakening of the bonding strength between them. In this condition, crack bridging (initiation and propagation of crack between two particles) takes place quickly between the neighbour corks (see Fig. (11)) which leads to cork coalescence and creating a larger damaged area inside the specimen.

Considering the present results, it can be concluded that there is an optimum amount of cork corresponding to the best adhesive fracture toughness and highest joint strength. The trend presented by the bulk results (Fig. (7)) is different from that shown by the SLJs results (Fig. (9)). It is mainly because the bulk specimens are loaded in tension and the SLJs are 
loaded in shear. The tensile properties are highly influenced by the voids while the shear conditions are less sensitive to bubbles. Accordingly, it is concluded that the optimum amount of cork to obtain the best fracture properties of the specimens depends on the loading conditions.

\section{CONCLUSION}

he effects of cork volume fraction on the strength of SLJs with different overlap lengths were studied. SEM was employed to analyse the fracture surfaces of bulk specimens and SLJs. A SEM analysis of the fracture surface of bulk specimens showed that increasing the volume fraction of micro cork causes considerable cleavage failure in the fracture surface of the specimens which results in higher energy absorption and higher toughness of the adhesives containing $1 \mathrm{vol} \%$ of micro particles. On the other hand, the results of the tested SLJs showed that the static strength of SLJs increase with cork volume fraction up to $5 \mathrm{vol} \%$. According to the results, $5 \mathrm{vol} \%$ of cork particles increased the failure loads of the tested joints with $25 \mathrm{~mm}$ overlap length up to $70 \%$. It was shown that the cork particles act as a crack stopper and consequently stabilize the crack propagation and prevent the development of large and unstable cracks. This leads to more energy absorption which increases the fracture loads of the specimens. On the other hand, higher content of cork increases the possibility of agglomeration of the particles, acting as a source of stress concentration, with a higher possibility of delamination between the matrix and the micro corks and also causing the formation of a very thin adhesive layer between adjacent particles. Accordingly, there is an optimum amount of cork where the best adhesive fracture toughness and joint strength are reached. The results of the bulk and the SLJ tests also showed that the optimum amount of cork may vary depending on the loading conditions.

\section{ACKNOWLEDGEMENTS}

$\mathrm{F}$ inancial support by Foundation for Science and Technology (PTDC/EME-TME/098752/2008 and SFRH / BD / 88173 / 2012) are greatly acknowledged.

\section{REFERENCES}

[1] Adams, R.D., (2005). Adhesive bonding: science, technology and applications, Elsevier.

[2] Banea, M. D. da Silva L.F.M. Campilho and R. D. Sato, C. (2014). Smart adhesive joints: an overview of recent developments, J. Adhes. 90(1), pp. 16-40.

[3] Huang, Y., Kinloch, A., Hunston, D. and Riew, C. K. (1993). Mechanisms of toughening thermoset resins. American Chemical Society, Washington, DC (United States).

[4] Barbosa, A., da Silva, L.F.M., Banea, M. and Öchsner, A. (2016). Methods to increase the toughness of structural adhesives with micro particles: an overview with focus on cork particles, Materialwissenschaft und Werkstofftechnik. 47(4), pp. 307-325.

[5] Cardwell, B. and Yee, A. (1998). Toughening of epoxies through thermoplastic crack bridging, J. Mater. Sci. 33(22), pp. 5473-5484.

[6] Silva, M., Marques, E. and Silva, L.F.M. (2016). Behaviour under Impact of Mixed Adhesive Joints for the Automotive Industry, Latin American J. Solids Struct., 13(5), pp. 835-853.

[7] Ramos, V.D., da Costa, H.M., Soares, V.L. and Nascimento, R.S. (2005). Modification of epoxy resin: a comparison of different types of elastomer, Polymer Testing. 24(3), pp. 387-394.

[8] Barbosa, A., da Silva, L.F.M., Öchsner, A., Abenojar, J. and del Real, J. (2012). Influence of the size and amount of cork particles on the impact toughness of a structural adhesive, J. Adhes. 88(4-6), pp. 452-470.

[9] Barbosa, A., da Silva, L.F.M. and Öchsner, A. (2015). Hygrothermal aging of an adhesive reinforced with microparticles of cork, J. Adhes. Sci. Technol. 29(16), pp. 1714-1732.

[10]Gil, L. (2009). Cork composites: a review, Materials. 2(3), pp. 776-789.

[11]Mano, J.F. (2002). The viscoelastic properties of cork, J. Mater. Sci. 37(2), pp. 257-263. 
[12] Sierra-Pérez, J., Boschmonart-Rives, J., Dias, A.C. and Gabarrell, X. (2016). Environmental implications of the use of agglomerated cork as thermal insulation in buildings, J. Cleaner Production. 126, pp. 97-107.

[13]Hernández-Olivares, F., Bollati, M., Del Rio, M. and Parga-Landa, B. (1999), Development of cork-gypsum composites for building applications. Construction and Building Materials, 13(4), pp. 179-186.

[14]Barbosa, A., da Silva, L.F.M. and Oechsner, A. (2014). Effect of the amount of cork particles on the strength and glass transition temperature of a structural adhesive, Proceedings of the Institution of Mechanical Engineers, Part L: Journal of Materials Design and Applications, 228(4), pp. 323-333.

[15]Barbosa, A., da Silva, L.F.M., Abenojar, J., del Real, J., Paiva, R.M. and Öchsner, A. (2015). Kinetic analysis and characterization of an epoxy/cork adhesive, Thermochimica Acta. 604, pp. 52-60.

[16]Barbosa, A., da Silva, L.F.M., Abenojar, J., Figueiredo, M. and Öchsner, A. (2017). Toughness of a brittle epoxy resin reinforced with micro cork particles: Effect of size, amount and surface treatment, Composites Part B: Engineering. 114, pp. 299-310. 